\title{
Major Causes for Problems with English Education in China
}

\author{
Tian Qiang, Li Huijie \\ Harbin Institute of Technology, China
}

\begin{abstract}
Our research study is focus on the major causes that are responsible for the problems afflicting English education in China (EEC), from different perspectives. In terms of history, EEC was not built on a wholesome and well-connected foundation; in terms of structure, EEC is ineffective due to an incomplete administrative faculty and a poorly connected system; in terms of practice, EEC suffers from a misplaced identity (linguistic instead of educational) and deviated focus; in terms of cognition, EEC suffers from poorly conceived ideas, including mistaking intercultural communication for the goal of EEC and misplacing testing on an unduly high position. It is the interweaving work of these causes that not only ends in the "high timeconsumption and low efficiency" of EEC but also makes it so resistant for correct diagnosis and effective cure.
\end{abstract}

\section{Introduction}

Though the glamorous achievements of English education in China (EEC) have been sensationally felt by the whole world, whether in job market, educational institutions or supermarkets, it has been increasingly under the attack of its "high timeconsumption and low efficiency". Various demonstration of that chronic illness are but symptoms of a syndrome with a complicated interweaving network of many causes at work.

As cures will never come without the discovery and acknowledgment of the major causes and the distinction of the nature of relations between them, a search for the causes may mean the start toward the only justifiable solution, and the following is nothing more than an attempt in that direction: A trial exploration of the major causes for the problems with EEC.

\section{Heritage, a disabled baby}

Heritage is in a sense a child of history. In that sense all incidents and accidents of any kind in the externality during the pregnancy leave impacts upon the child, physically and mentally, as is shown in his physiological, psychological and behavioral features.

\subsection{What EEC was like in Old China}

The social education as a system in China used to be, before the end of the 19th century, equipped with a faculty suited to the static nature of knowledge in the dynastic, centralized system, which had its very origin in the contention and flourishing of numerous schools of thought during Autumn and Warring States era $(770-221$ BC) [1]. But the first two decades of the 20th century witnessed the demolition of the system of that faculty, first in form and then in essence, in face of the intruding Western cultures.

Reconstruction had never been completed in educational faculty, as it was in most other fields or walks of life. Considering the all lasting warring condition, that was acceptable as the only consequence. In spite of that, there was some makedo or temporary establishments in effect. In terms of EEC at the college level, there was an almost whole set of institutions reasonably suited to the elite traits of higher education at that time, as was pointed out by Tian \& Qiao [2]:

English education was conducted in various educational institutions, including public and private ones in ownership, and governmentsponsored and church-sponsored in funding and management.

The English education covers both the specialty education and the general education. As there was condition - in terms of teaching materials and teaching staff - for specialty education in Chinese, practically all specialty education was carried out in English. Most students were eager to arm themselves with knowledge learned through English.

The priority of literature was a remarkable facet of that set, showing an outstanding feature of the "Saloon English", as the learners were little concerned with employment but wholly keen to one's own level of "literary cultivation".

Materials were arranged in system and in sequence, in accordance with the genre division and the from-easy-to-difficult development. 
Independent learning was encouraged, insofar as learning efforts were made.

The syllabus much less "occupied" with classes compulsory in form or in effect, leaving learners to independent learning. Syllabus intact and learning pure, with practically no "nationwide unified examination" or irrelevant activities to break or interrupt the process of learning.

\subsection{The "transformation" of EEC in the 1950s and 1960s}

The 1950s and 1960s witnessed a winding-in-form but about-turn-in-nature change of EEC in most of the cardinal aspects.

Though New China initially took a positive attitude towards EEC, as was shown in the inclusion of English in the general system of public education, and introduction of nationwide unified examination, that attitude changed fundamentally with the deterioration of the relation between New China and the Western World, due, among other things, to the Korean War.

That inclination reached a freezing point with the implementation of Overall-Inclination (towards USSR) policy and the corresponding "Adjustment of Institutions and Specialties" in 1952. EEC was almost all abandoned in the ensuing 4 years, with the exception of 300-odd learners in the English major and a teaching staff of about 110 members [3].

The year 1956 saw the reconstruction of EEC, which, coinciding with such movements as Antirightist Movement in 1957, which acted as a heavy blow on the intellectuals, the Great-Leap-Forward, which stripped all efforts of a rational foundation and framework, and the implementation of "the Guiding Principles of Education", which bent EEC over towards an excessive political tendency.

Real reconstruction of EEC did not come until 1961 when China had survived the three years of great famine and took a more rational attitude towards the world. By 1963, a new model of EEC had been finished as a whole. It was in the succeeding three years that EEC saw its first bunch of achievements in the history of New China, as could be seen at the college level [4]:

English was required to be taught in college.

National textbooks were compiled for the

English majors and the non-majors at college

level, and for the latter purposes of human

science and natural science were specifically

served. The first national syllabus was designed

for the non-majors, and a "Seven-Year Plan"

was made for further development.

But the reconstruction was incomplete of faulty, as can be seen in the following aspects [4]. English education became unrelated with specialty sphere, a break with the tradition of EEC prior to 1949.
The focus of EEC was mainly on the language aspects, and only materials that showed the negative aspects of the Western world could be used culturally.

Teaching and learning activities were focusing increasingly on textbooks, extracurricular activities were rare; a collective mode of learning, instead of the previous individual and independent one, was encouraged.

These features obviously retarded the EEC learners' sensitivity to the integrity of linguistic knowledge and the more life-related knowledge in the specialty and general spheres. Yet due to the distribution instead of employment policy upon graduation of college students, such serious faults or shortcomings were casually or deliberately hidden.

Yet even a such incomplete growth was allowed only 3 years. In 1966, the so-called "Cultural Revolution" brought EEC to a sudden but more lasting halt. When that disastrous age was over in the late 1970s, pieces of what EEC was between 1963 and 1966, rather than what it had been prior to 1949 , were picked up and sewn into the foundation or framework of EEC for the coming decades.

On a serious note EEC today is founded on a faulty foundation as the heritage we took over 3 decades ago was neither complete nor healthy. Most of the problems, especially the key ones, have hitherto been left attended.

\section{Structure: an ineffective design}

The EEC is ineffective as a structure, as is shown in the incomplete administrative faculty and the poorly connection of its component parts.

\subsection{The incomplete administrative faculty}

A wholesome administrative faculty is usually an integrity of at least three types of functional members: the administrative bureaucrats, who are capable of decision and enforcement; the technical bureaucrats, who are capable of planning and designing, on the selective basis of the whole sets of suggestions and advice from the professional experts, who as a whole cover every effective part of the structure and as individuals familiarize themselves with the structure organically and functionally.

The problems with the administrative faculty of EEC are shown, among other things, in the sever scarcity of technical bureaucrats, the transgression of the often professionally untrained administrative bureaucrats at nearly all levels, and the inadequacy of professional experts.

Taking the example of EEC at the higher education level. Policy-making and administration of English education in all higher educational institutions are in the hands of two groups of people: 
officials and staff members from the Humanity Section under the Higher Education Department as the administrative bureaucrats, and the members of College English Supervising Committee or the National Foreign Language Teaching Higher Steering Committee (or their sub-committees) as the professional experts. As the latter group(s) are composed mostly of experts in such academic areas as English \& American Literature, Linguistics and Translation, and each of them, though expertly trained and admirably accomplished, focuses his/her academic interest on a particular "point" or "points" for studies; their interests and viewpoints, even finely pinned together, may sometimes turn out to be incomplete or even fragmental in coverage, and incomplete in consideration. And advice of this kind is left, as it is, to the disposal of such unspecialized hand as those administrative bureaucrats.

\subsection{The poorly connected system of educational institutions}

The function of education is shown most evidently in the educational institutions as a system. Tight connection and smooth coordination are the hallmarks of the well-being of a system.

The problems with the educational faculty of EEC as a system are most easily spotted in the poor connection and coordination between the successive levels, as the component parts of the system. Even the comparatively best organized parts, the primary, secondary, and higher education levels, are fairly isolated from each other, each being ignorant of the function and operation of the other parts, far from being an integration of the component parts. The administration of EEC is incomplete in composition and its system is poorly connected and coordinated.

\section{Practice: misplaced identity and deviated focuses}

The quality or label word of EEC (English education in China) is education, signifying that the nature of EEC should be education rather than otherwise. But in the practice of EEC, the nature of EEC are mistakenly identified and devoted.

\subsection{Misplaced identity, as is seen in the problem with the disciplinary affiliation}

A key question about the identity of EEC or its disciplinary affiliation is: Is EEC linguistic or educational by nature? The misplaced disciplinary affiliation has been there almost all the time for the last few decades. In the academic classification at the state and the succeeding levels, there is no such a distinctive term as "English" or "English education". English education is usually found either as a subordination of "Foreign Languages and Literature", as is the level of the undergraduate which had been the norm prior to the late 1990s, or "Linguistics Abroad", as is at the level of the graduate - which is found in practically all English majors as an assumed license for existence and operation. But never has it been granted the identity as a distinctive part of education, and rarely has it been treated educationally.

Table 1. Major components /or issues of EEC as a system of education

\begin{tabular}{|l|}
\hline 1. EEC as an independent and distinctive identity \\
\hline 2. Issues concerning EEC as a system or a structure \\
\hline 3. Theoretical issues of EEC \\
\hline 4. Meta-education and philosophy of EEC \\
\hline 5. Position of EEC in China's social educational system \\
\hline 6. Historical development of EEC \\
\hline 7. Purpose or goals of EEC \\
\hline 8. Content and epistemological issues of EEC \\
\hline 9. Syllabus and course system of EEC \\
\hline 10. Mode and method studies of EEC \\
\hline 11. Teachers of EEC \\
\hline 12. Vocational or occupational education of EEC \\
\hline 13. Facilities and conditions of EEC \\
\hline 14. Achievement assessments in EEC \\
\hline 15. Environmental issues of EEC \\
\hline 16. Psychological issues in EEC \\
\hline 17. Relationship of EEC with social practice \\
\hline 18. Position of Chinese in EEC \\
\hline 19. Family education of EEC \\
\hline
\end{tabular}

Yet, as it can be easily seen, neither EEC as part of "Foreign Languages and Literature" or as part of "Linguistics Abroad" can explain its position in the system of public or social education in China. Nor can it explain the nature of EEC, its compositions, functions, and other fundamental issues. Many essential parts and key issues of EEC as a system of education [5] have in fact been left unattended throughout (see Table 1).

Unlike the case of language education in the US and in Western Europe, where the cognitive foundation is solid and epistemological framework is ready-made, linguistic treatment of EEC has proved deviated in direction and incomplete in coverage.

\subsection{Academics-obsessed teaching staffs}

All educational endeavors should be practiceoriented, and EEC, as a form or part of education, is no exception. The problem is that teachers of EEC, especially those in the top strata of the educational hierarchy, have devoted much of themselves to "academic studies". What they are doing is nothing 
but justifying their simplistic performance with sophisticated and profound theoretical bracing measured with a foreign yardstick. Some even manage to steer their "research" clear of teaching or to keep themselves far away from any educational waters.

Meanwhile, the tradition of practice-orientedness, which was commonly conducted before the 1990s, is overwhelmingly undervalued or neglected among the ordinary teaching staff, even unknown to the young ones.

Theoretical efforts may be better conducted with a top-down approach but practical efforts are preferable to a bottom-up approach, and education is ultimately practical in nature. Obsession with academics in EEC will cause an inevitable reduction in the quality of performance

\subsection{Test-devoted learners}

The path of EEC is comparable to a highway of typical contemporary Chinese features, with the only "visible landmarks" being various tests or examinations, like one toll-gate after another along the highway. The process of traveling is thus broken into numerous segments and what is left in the memory is often nothing but going through these "passes" irrelevant to the nature and function of the traveling. Though EEC cannot go without examination for the time being and in the foreseeable future (which is to be explained later), the sheer dominance of examination and re-division of the process of learning severely damages its form and function.

Moreover, the system and regularity of knowledge should not overlap those in examination, and there should not be anything in the examination showing its "regularity". Any recognition or "finding" of such regularity simply claims the overall or partial failure of the examination involved, because the prospective testees will inevitably devote themselves to "rearranging" what they are learning in order to match this regularity and that will in turn give them better chance in the oncoming examination. (This practice is extremely popular among the learners of English in China who are preparing for examination of some kind. It is the "open sesame" of a lot of businesses which are specialized in finding the regularity of examinations and then sell it to the corresponding testees. Some electronic devices are even labeled with " $\mathrm{X} \%$ findings of the regular items" in certain nationally or regionally unified examinations). But the rearrangement of learning efforts in accordance with the arrangement of examination means the destruction of the system and regularity of knowledge. This not only brings about the ensuing deficiency, but also has lasting impact, at least upon the learners' cognition of knowledge and habitual behaviors in learning, which are much direr in consequence.

The internal well-being of EEC is equally disturbing both in terms of its erroneous selfconsciousness and the poor quality of performance by its practitioners (teachers and learners).

\section{Cognition: leaky but self-assertive paradoxes}

Concepts concerning EEC are cognitively erroneous, though such errors are taken for granted, or even treated with applause.

\subsection{Function of EEC for the purpose of intercultural communication}

This notion is highly popular among both the professionals or practitioners and learners or their guardians (who are often the decision-makers on for what purpose, what and how to learn in the case of EEC, especially at the primary and secondary levels). But this positioning commits errors in several senses. It is contradictory to the function of language as is seen from the perspective of education. Though commonly hailed as "means of communication", in the particular sense of education, a language is in the first place the carrier of knowledge" [6]. The learning of a language, for the educated, is thus for the purpose of learning knowledge instead of communicating with another one.

Secondly, it is in violation of the principle of communication. Communication is, by nature, a kind of exchange. For any exchange to be substantially executed, those who are involved in it must be loaded with "something" to be exchanged with. Thus before any exchange, there must be some kind of "loading", which is often in the form of education. Furthermore, communication can hardly be the "ends", but merely the "means", as each of those who are involved in communication usually has a purpose of his or her own, which he or she hopes to achieve or accomplish through the communication. Indeed, the dimensions of the purpose vary enormously, ranging from "the conquest of the world" to "killing the boring ten minutes".

Finally, the prospect is still too rosy to be true for most ordinary EEC learners. For the absolute majority of them, even at the level of higher education, the opportunity of face-to-face communication with an English-speaking foreigner is infrequent, or even rare, and the hard-earned opportunity may prove ornamental instead of functional. To put it in a metaphorical way: If Cinderella or her likes spends almost all her life preparing for the attendance of a single ball party, her behavior is not rationally worthy. Cinderella is exceptional because there is only one prince, and she 
never knows that experience will mark a complete change in her fate. Life is based on reason rather than speculative reveries.

Taken all in all, the functional aim of EEC as "means of intercultural communication" is still elite in nature and not feasible for the majority of learners, even if it looks rosy and sounds charming.

In the last three decades, public education in China, at the level of higher education, has outgrown the transformation from elite education to mass education, as is measured with Trow's yardstick [7]. But, as it happens in many cases, theoretical or cognitive preparation is far from being ready. In the case of EEC, where the problems caused by inadequate or erroneous cognitive preparation are more frequently seen and more severe in consequence; the attention is not yet in the right direction and the constructive endeavor, certainly, not on the right track. For instance, the role of EEC in elite education, whose purpose is train leaders for the society, is definitely different from its role in general education, whose purpose to prepare ordinary members of the society for his or her betterment in life.

\subsection{Testing as justifiable motivating power of EEC}

The attitude towards the role of testing in EEC presents an outstanding example of paradox. People inside and outside the endeavor, from the top administrators to the ordinary teaching staff, are defaming testing all the time, treating it as an equivalent of Satan. But, while they defame it, they defer to it, at almost every minute and in every maneuver, as a "baton" in manipulating the operation of EEC.

It is essential for any rational endeavor that "landmarks" of some kind be provided not only to remind those involved in the endeavor of their position in the progress, but also to encourage and vitalize them with their achievements. In any educational endeavor, the "landmarks" also serve as scales to measure the size of the achievements and as connecting devices between education and the daily life.

Table 2. Set of education in a normal condition

\begin{tabular}{|l|l|l|}
\hline $\begin{array}{l}\text { Purpose and } \\
\text { motivation }\end{array}$ & $\begin{array}{l}\text { The overall purpose or goal of education (conceivable to the senses or foreseeable to } \\
\text { the mind) }\end{array}$ \\
\hline Content & Materials in whole set or system as is required by the overall purpose or goal \\
\hline \multirow{2}{*}{ Method } & Macroscopic & Teaching as a system (The arrangement and layout of Materials) \\
\cline { 2 - 3 } & Microscopic & Teaching as a process (The concrete handling of materials) \\
\hline
\end{tabular}

Table 3. The should-be position of testing in the layout of EEC

\begin{tabular}{|l|l|l|}
\hline $\begin{array}{l}\text { Purpose and } \\
\text { Motivation }\end{array}$ & $\begin{array}{l}\text { The overall purpose or goal of education (conceivable to the senses or foreseeable to } \\
\text { the mind) }\end{array}$ \\
\hline Content & Materials in whole set or system as is required by the overall purpose or goal \\
\hline Method & Macroscopic & Teaching as a system (The arrangement and layout of Materials) \\
\cline { 2 - 3 } & Microscopic & Teaching as a process (The concrete handling of materials) \\
\hline
\end{tabular}


Table 4. The actual position of testing in the layout of EEC

\begin{tabular}{|l|l|l|}
\hline $\begin{array}{l}\text { Purpose and } \\
\text { motivation }\end{array}$ & $\begin{array}{l}\text { The overall purpose or goal of education (conceivable to the senses or foreseeable to } \\
\text { the mind) }\end{array}$ \\
\hline Content & Materials in whole set or system as is required by the overall purpose or goal \\
\hline \multirow{2}{*}{ Method } & Macroscopic & Teaching as a system (The arrangement and layout of Materials) \\
\cline { 2 - 3 } & Microscopic & Teaching as a process (The concrete handling of materials) \\
\hline
\end{tabular}

In the case English education in its native countries, as that of teaching of Chinese in China, or in an environment with a ready-made set of "digestive" or "integrative" facilities, what is learned through English almost immediately and unconsciously becomes a natural part of the learner's up-to-date life. But in China where no such facilities are readily available for EEC, artificial facilities have to be provided to save the learners from "aimless learning", and the most feasible form of artificial facilities is testing. In summary, EEC cannot go without testing.

Yet that does not justify the type of test-oriented practice of EEC now. The problem with EEC in relation to testing lies not in the feasibility of testing itself, but in the position of testing in the system of EEC.

A comparison may probably lead us to the discovery of what is structurally and functionally wrong with testing in EEC now [7].

In a normal condition, a functional system, or a functional set in the system of public or social education is, as a logical "circuit", composed of the following components:

Considering the absence of "visible goals or targets" in the externality of EEC, an artificial set of "visible goals or targets" has to be set, and that set is composed of reasonably testing. The mode of EEC is thus "test-oriented" in a certain sense.

Yet the mode of EEC, as is modified above, is only "test-oriented" in the sense that the top layers of "purpose and motivation" and "content" is unaffected by the presence of testing. Or, to be more concrete, the "orienting" power of tests is seen only in the realm of "method" in the "microscopic" sense. The "feedback" function of testing is used only on the condition that the purpose, the content system, and the overall arrangement are readily available, as shown in Tables 2 and 3.

If such an arrangement is justifiable, then the problem with the status quo of test-orientedness in EEC is easily recognizable (see Table 4 next page).
Such an embarrassing position of testing is responsible for or related to practically all of the problems with testing-orientedness of EEC, and is also responsible for the unworthy claims on it.

We are not clear about what we are doing. But some of us are so ignorant of our ignorance that they firmly but unfoundedly hold that they are. The wisdom of Socrates - "I know that I don't know" that's what is needed for EEC in the first place.

\section{Conclusion}

English education is a necessity in China. The history and reality of EEC has made it another undeniable fact that it is so different in nature from its peers - if there have been or are some - that nothing is readily available as a reliable format or a framework.

A conclusion can be drawn from the above discussion: Various causes are responsible for the present faulty situation and problems. It is the interweaving work of theses causes that only merely renders EEC "high consumption but low efficiency" but also makes it a headache for diagnosis and cure.

Yet neither denial nor neglect can serve as the real cure. A face-to-face encounter with and a close, patient look into the causes of the problems in EEC may not come immediately up with a ready solution to these problems, but it is definitely the only correct direction towards their real solution.

\section{Acknowledgements}

Supported by the projects "A Study of the Ontological Basis of the Entrance Examination of English for Postgraduates in China" (Project No: GFA 111021); "A study of English Education in China's Universities from an Educational Approach" (Projects No: 12B042, HIT. HSS. 201231); "Fundamental Research Fund for the Central Universities" (HIT. HSS. 2009007). 


\section{References}

[1] Chen, Q. Z., A history of education in China, Oriental Press, Beijing, 2008, P33.

[2] Tian, Q., and Qiao, H., "A Study on the Features of English Education in Old China's Universities and Its Implications", China Examination, Beijing, 2014, Issue (6), pp36-44.

[3] Fu, K., A History of Foreign Language Education in China, Shanghai Foreign Language Education Press, Shanghai, 1986, pp60-61.

[4] Tian, Q., and Qiao, H., "Three Models of English Education in China's Universities-A Historical Perspective", Sino-US English Teaching, David Publishing Company, 2013, Vol. 10, No. 9, pp676-684.

[5] Q. Tian, J. Cai and Qiao, H., "Some Ontological Issues on English Education in China's Universities", USChina Education Review, David Publishing Company, Vol (12), pp658-666.

[6] Borgatta, E. F., (editor-in-chief), Encyclopedia of sociology, New York: Macmillan Reference, 2000, P798.

[7] Trow, M., "Twentieth-century higher education: Elite to mass to universal", College Quarterly Fall, 2010, 15(4). Retrieved from http://www.collegequarterly.ca/ 2012vol15-num04-all/doughty5.html (Access Date: 12 February, 2015). 